\title{
Triggered Rapid Degradation of Nanoparticles for Gene Delivery
}

\author{
José M. Morachis, ${ }^{1}$ Enas A. Mahmoud, ${ }^{1}$ Jagadis Sankaranarayanan, ${ }^{1}$ and Adah Almutairi ${ }^{1,2}$ \\ ${ }^{1}$ Skaggs School of Pharmacy and Pharmaceutical Sciences, University of California at San Diego, 9500 Gilman Drive, MC 0600 La Jolla, \\ CA 92093-0657, USA \\ ${ }^{2}$ Materials Science and Engineering Program, University of California at San Diego, 9500 Gilman Drive, MC 0600 La Jolla, \\ CA 92093-0657, USA
}

Correspondence should be addressed to Adah Almutairi, aalmutairi@ucsd.edu

Received 22 February 2012; Revised 1 May 2012; Accepted 4 May 2012

Academic Editor: Juan M. Irache

Copyright (C) 2012 José M. Morachis et al. This is an open access article distributed under the Creative Commons Attribution License, which permits unrestricted use, distribution, and reproduction in any medium, provided the original work is properly cited.

\begin{abstract}
Effective gene delivery tools offer the possibility of addressing multiple diseases; current strategies rely on viruses or polyplexes. Encapsulation of DNA within nanoparticles is an attractive alternative method for gene delivery. We investigated the use of our recently developed Logic Gate Nanoparticle for gene delivery. The nanoparticles, composed of a dual pH response random copolymer (poly- $\beta$-aminoester ketal-2), can undergo a two-step "in series" response to endosomal pH. The first sep is a hydrophobic-hydrophilic switch, which is followed immediately by rapid degradation. Rapid fragmentation is known to increase cytoplasmic delivery from nanoparticles. Therefore, we hypothesized that our Logic Gate Nanoparticles would enable increased gene delivery and expression relative to nanoparticles that degrade more slowly such as PLGA-based nanoparticles. Passive nanoparticle entry into cells was demonstrated by delivering Cy5-labeled pDNA encoding EGFP into HCT116, a colon carcinoma cell line. Flow cytometry analysis showed that cells are positive for Cy5-DNA-nanoparticles and produced EGFP expression superior to PLGA nanoparticles. Inhibition of V-ATPases using bafilomycin A1 demonstrates that expression of EGFP is dependent on low endosomal pH. The advanced Logic Gate Nanoparticles offer new therapeutic possibilities in gene delivery and other applications where rapid release is important.
\end{abstract}

\section{Introduction}

Emerging gene delivery tools offer novel therapeutic approaches to address several types of diseases including progeria, cystic fibrosis, Parkinson's, and multiple types of cancers. Gene therapy encompasses the entire process of effectively delivering functional DNA into cells to replace a missing or mutated gene within malfunctioning cells. One of the main challenges with gene delivery is that free DNA circulating in the body is exposed to nuclease degradation. Additional obstacles for gene delivery include the inability of DNA to cross the cell membrane, escape the endosome, and enter the nucleus due to the DNA's size and negative charge. Though virus-mediated delivery of DNA offers high transfection efficiencies and high expression rates [1], viral vectors face several fundamental problems including toxicity, immunogenicity, and high manufacturing costs $[2,3]$.
Nonviral polymeric systems offer an attractive alternative to deliver plasmid DNA and other nucleic acid molecules like siRNA, as they are generally less immunogenic [4-7]. However, polymeric systems must overcome various challenges to induce gene expression. In order to promote high efficiency of gene delivery, DNA must escape from the endosome before degrading within the late endosome and lysosome. A method that is widely used to promote endosomal lysis is to include chloroquine within the formulation [8]. A drawback of chloroquine, however, is that it can disrupt potentially all the endosomes and lysosomes in the cell $[9,10]$. Advances in cationic polymers such as poly (L-lysine) (PLL) and polyethyleneimine (PEI), PAMAM dendrimers, and chitosan have shown some promise in complexing DNA into polyplexes and use for DNA delivery in vivo [11-15]. The positively charged complexes allow binding and entry into the negatively charged cell membrane. Additionally, the large number of amino groups in PEI and other polymers 
offers a buffering effect in the low $\mathrm{pH}$ environment of the endosome and creates a "proton sponge" leading to endosomal burst and release of the DNA complex into the cytoplasm to produce higher transfection efficiencies [16].

Because polyplexes cause toxicity and are relatively unstable, nano- and micro-particles provide an alternative method for delivery. Nanoparticles provide superior protection from circulating nuclease activity and offer an array of possible targeting advantages when combined with specific peptides. Nanoparticles composed of synthetic polymers such as poly(lactic-co-glycolic acid) (PLGA) are safe and attractive methods for DNA delivery applications and have been used in several studies [17]. Encapsulation of DNA with PLGA protects it from nuclease degradation, but the DNA is released slowly over time as PLGA degrades through ester hydrolysis $[18,19]$. An additional limitation of using PLGA nanoparticles is their negative charge that must be modified to reduce this barrier to DNA encapsulation and delivery [20].

In this paper, we investigated a novel gene delivery system using Logic Gate Nanoparticles developed with a dual $\mathrm{pH}$-responsive random copolymer (poly- $\beta$-aminoester ketal-2, Figure 1) [21]. Current pH-responsive polymers have been demonstrated and are promising gene delivery systems [22]. However, our random copolymer is unique because it remains hydrophobic at physiological $\mathrm{pH}(\mathrm{pH} 7.4)$ but undergoes a switch from hydrophobic to hydrophilic at low endosomal $\mathrm{pH}$, which initiates rapid fragmentation into small molecules. The amine moieties in the backbone undergo a sharp hydrophobic-hydrophilic switch. This leads to an increase in water uptake (bulk dissolution) and hence an increase in ketal hydrolysis (degradation) [23]. The nanoparticle formulations are stable for 24 hours in physiological $\mathrm{pH}$ [21], as TEM revealed well-formed particles, and upon reducing the $\mathrm{pH}$ to endosomal levels, $\mathrm{pH}$ 5, these dual responsive nanoparticles undergo a rapid and dramatic fragmentation followed by concomitant release of their payloads (Figure 1). We hypothesized that these nanoparticles would be suitable for gene delivery and efficient gene expression. In this study, we demonstrate that nanoparticles composed of the dual $\mathrm{pH}$-responsive polymer offer effective endosomal release and expression of encapsulated DNA due to its ability to undergo rapid fragmentation.

\section{Materials and Methods}

2.1. Materials. Dichloromethane (DCM, methylene chloride) and trehalose were purchased from Fisher Scientific (Hampton, NH, USA). Poly (vinyl alcohol) (PVA) (MW 30-70 k) and bafilomycin Al were obtained from Sigma Chemical Co. (St. Louis, MO, USA). PLGA (Resomer RG 502H) was purchased from Boehringer Ingelheim (Germany). Cy5 labeling kit was obtained from Mirus Bio (Madison, WI, USA). Cell culture media was purchased from Life Technologies (Carlsbad, CA, USA). All reagents were purchased from commercial sources and were used without further purification unless otherwise stated.
2.2. Plasmid Preparation and Cy5 Labeling. The pEGFP plasmid was expanded in overnight cultures of DH5 alpha E. coli cells and purified using maxi prep kits (Life Technologies). The DNA was Cy5-labeled using the Label IT Tracker Intracellular Nucleic Acid Localization Kit (Mirus, USA). In brief, the DNA plasmid was incubated with Label IT tracker reagent in the labeling reaction at $37^{\circ} \mathrm{C}$ for $1 \mathrm{hr}$. Then, labeled DNA was separated from free dye using Micro Bio-Spin 30 chromatography columns (BioRad, Hercules, CA, USA).

2.3. Synthesis and Characterization of Poly- $\beta$-Aminoester ketal-2. Following the literature procedures and in agreement with previously described polymer characterization [21], the polymer was prepared by Michael addition of the corresponding diacrylates with trimethyl dipiperidine. Molecular weight was estimated by size exclusion chromatography against polystyrene standards in DMF/0.01\% $\mathrm{LiBr}$ with a VWD (variable wavelength detector) at $250 \mathrm{~nm}$. $\mathrm{Mw}=6300, \mathrm{Mn}=2880$, and $\mathrm{PDI}=2.18$.

2.4. Preparation of Nanoparticles. The nanoparticles were prepared using PLGA or the $\mathrm{pH}$-responsive polymer using $\mathrm{W} / \mathrm{O} / \mathrm{W}$ method. In a vial, $10 \mathrm{mg}$ of the polymer was dissolved in $300 \mu \mathrm{L}$ of DCM. Subsequently, $30 \mu \mathrm{L}$ DNA solution prepared in Tris- $\mathrm{HCl}$ buffer $\mathrm{pH} 8$ was added. The two phases were sonicated for $30 \mathrm{~s}$ at $6 \mathrm{~W}$ (amplitude of 2, Misonix S-4000, 5.5" cup horn, USA). Then, an aqueous solution of $3 \mathrm{~mL} 1 \%$ PVA in Tris-HCl buffer $\mathrm{pH} 8$ was added and sonicated for two $30 \mathrm{~s}$ cycles at $7 \mathrm{~W}$ (amplitude of 5) using the same cup horn. The nanoparticle suspension was stirred at $500 \mathrm{rpm}$ under vacuum using a magnetic stirrer to evaporate DCM. A concentrated mode tangential flow filtration system using $500 \mathrm{kDa}$ MicroKros modules (Spectrum Labs) was used to remove the PVA and free DNA [24]. The nanoparticle suspension was concentrated and washed two times. Finally, the suspension was lyophilized after adding $5 \%$ trehalose. The nanoparticle characterization and properties were in agreement with the previously described literature [21]. In brief, dynamic light scattering (DLS, Malvern Zetasizer) revealed that $\mathrm{pH}$-responsive particles had $\mathrm{Z}$-average diameters of $300 \mathrm{~nm}(\mathrm{PDI}=0.3$, zeta-potential $=$ $-0.562 \mathrm{mV}$ in $\mathrm{pH} 8 \mathrm{~PB}$ ), and PLGA particles were $340 \mathrm{~nm}$ $(\mathrm{PDI}=0.37)$.

2.5. Nanoparticles Encapsulation Efficiency and DNA Integrity. To test the integrity and amount of encapsulated DNA in PLGA nanoparticles, $0.2 \mathrm{~mL}$ nanoparticles dispersion in $10 \mathrm{mM}$ Tris- $\mathrm{HCl}(\mathrm{pH} 8)$ was extracted with $0.2 \mathrm{~mL}$ phenol: chloroform: isoamyl alcohol $(25: 24: 1)$ and spun down at $12,100 \mathrm{~g}$ for $20 \mathrm{~min}$. Then, $50 \mu \mathrm{L}$ of the aqueous layer was diluted with $250 \mu \mathrm{L} 10 \mathrm{mM}$ Tris- $\mathrm{HCl}(\mathrm{pH} 8)$ and extracted with $300 \mu \mathrm{L} \mathrm{CHCl}_{3}$. The aqueous layer was separated by spinning down and analyzed by gel electrophoresis for DNA. To test the integrity of encapsulated DNA in the $\mathrm{pH}$ responsive nanoparticles, nanoparticles $(0.2 \mathrm{~mL})$ in $10 \mathrm{mM}$ Tris-HCl (pH 8) with heparin (1: 100 DNA to heparin), were extracted and analyzed as previously described with PLGA nanoparticles. To evaluate the encapsulation efficiency in 
PLGA (FDA-approved, slowdegradation kinetics)<smiles>C=C(CO)C(C)C(=O)O</smiles>

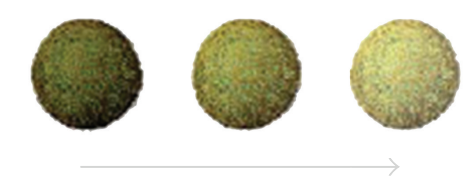

Logic Gate Nanoparticles (stable until triggered to rapidly fragment)

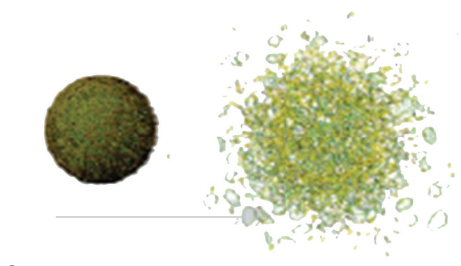<smiles>CCCC(=O)OCCOC(C)(C)OCCOC(=O)CCN1CCC(CCCC2CCN(CCC(=O)OCCCCCCOC(=O)CCN3CCC(CCCC4CCN(C)CC4)CC3)CC2)CC1</smiles>

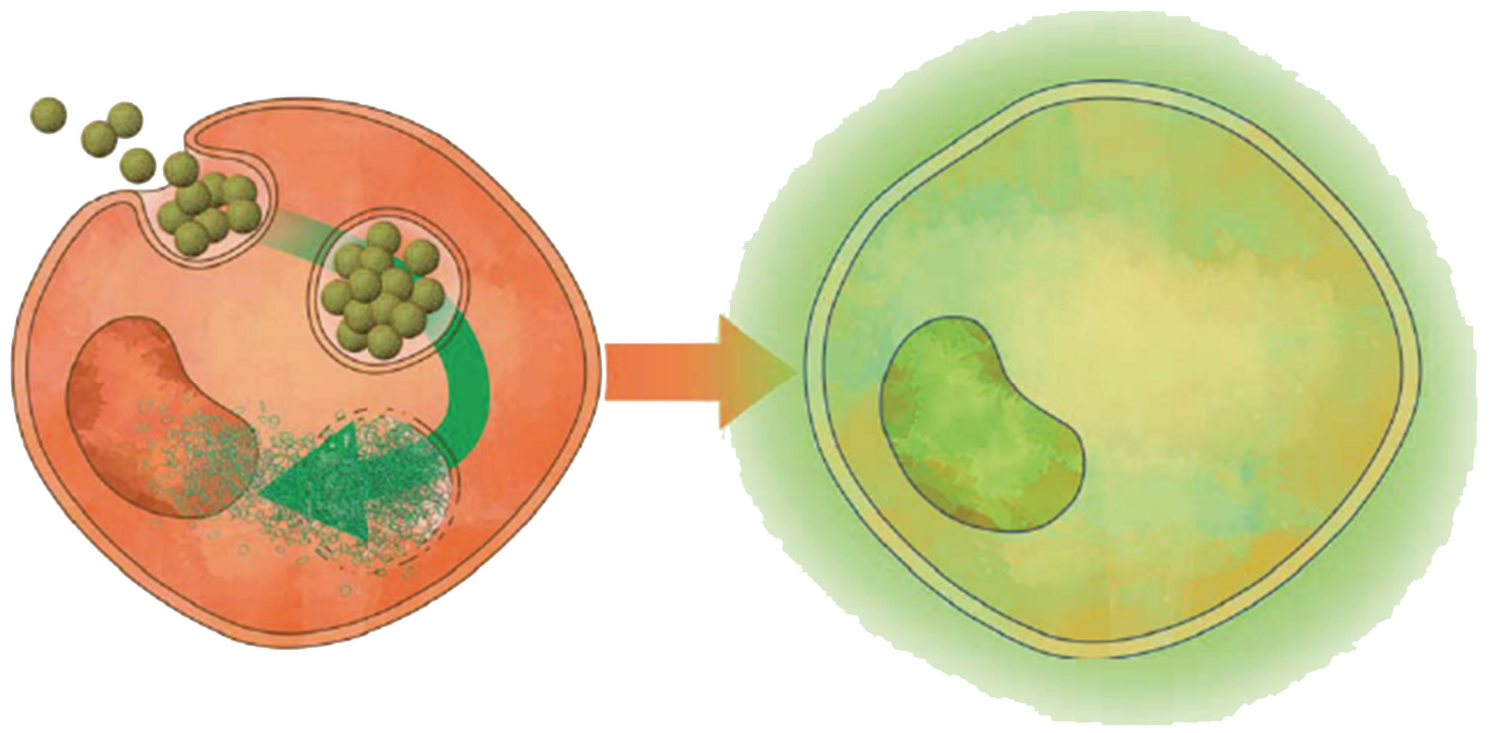

FIGURE 1: Schematic representation of the dual pH-responsive nanoparticles used for gene transfection.

the $\mathrm{pH}$-responsive nanoparticles, the collected filtrate through the tangential flow (see previous section) was lyophilized and resuspended to determine the amount of DNA using $1 \%$ TAE agarose gel.

2.6. DNA Release From the Nanoparticles. DNA-Cy5 nanoparticles were resuspended in phosphate buffer $\mathrm{pH}$ 7.4. The nanoparticles were left in a shaker at $60 \mathrm{rpm}$ and $37^{\circ} \mathrm{C}$. Aliquots were taken at different time intervals and spun down at 2,000 g and $4^{\circ} \mathrm{C}$ for $10 \mathrm{~min}$. The supernatant was used to determine the fluorescence of released DNACy5. After 24 hours, the particles were spun down and resuspended in phosphate buffer $\mathrm{pH} 5$ to test the effect of $\mathrm{pH}$ on DNA release from the nanoparticles.

2.7. Transfection of DNA with Nanoparticles. HCT116 cells were plated at $\sim 50 \%$ density in a 24 -well culture plate and allowed to attach overnight. Cells were then treated with nanoparticles encapsulating 50 to $100 \mathrm{ng}$ of labeled or unlabeled DNA for 30 minutes, 1, 2, 3, or 4 hours in the presence of regular media with $10 \%$ serum. The media was then replaced with $500 \mu \mathrm{L}$ of fresh media in each well after washing to remove excess nanoparticles. For DNA-Cy5 analysis, the cells were immediately analyzed by fluorescence microscopy (Nikon and NIS Elements software) and flow cytometry (Accuri C6) by detecting fluorescence in the far red spectrum $(670 \mathrm{~nm})$. To analyze GFP expression, the cells were treated with nanoparticles for 4 hours, then the media was replaced and incubated for 48 hours. The cells were subsequently analyzed by fluorescence microscopy or flow cytometry (Accuri C6) to detect green fluorescence. For microscopy analysis, cells were placed in wells containing glass coverslips. For flow cytometry, cells were first trypsinized for 5 minutes followed by two washes with PBS 


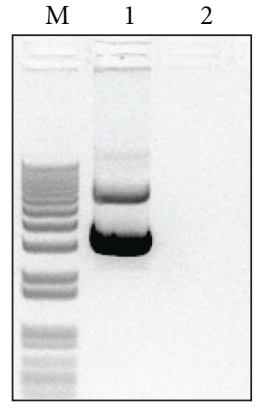

(a)

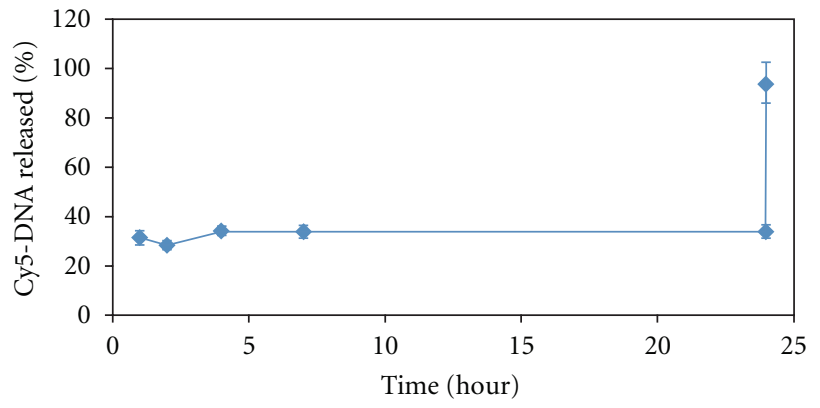

(b)

FIGURE 2: DNA encapsulation efficiency and release study. (a) DNA encapsulation efficiency was analyzed by comparing band intensity of control DNA (lane 1) to that of nonencapsulated DNA collected during the tangential flow filtration process (lane 2). (b) Cy5 fluorescence of released DNA from nanoparticles in buffer $\mathrm{pH} 7.4$ over 24 hours followed by addition of pH 5 buffer. The pH changes to 5 at 24 hours.

and analyzed immediately. To test the requirement for low endosomal $\mathrm{pH}$, cells were treated with Bafilomycin $\mathrm{A} 1$ at a final concentration of $300 \mathrm{nM}$ prior to adding nanoparticles. The cells were then incubated for 4 hours, followed by replacement of media and incubation for 48 hours.

\section{Results and Discussion}

3.1. DNA Encapsulation and Stability Study. Considering the obstacles to gene delivery, including DNA packaging, transport across the membrane, endosomal escape and transport into the nucleus, we aimed to demonstrate the effectiveness of our dual $\mathrm{pH}$-responsive nanoparticles to meet these challenges. We first determined the stability and effectiveness of DNA encapsulation in the dual $\mathrm{pH}$ responsive nanoparticles.

The dual $\mathrm{pH}$-responsive nanoparticles containing plasmid DNA were prepared with poly- $\beta$-aminoester ketal2 using a double-emulsion method. The supernatant and washes of the preparations were kept and analyzed to estimate the percent of nonencapsulated DNA. The encapsulation efficiency was estimated to be approximately $100 \%$ since no DNA was detectable in these fractions (Figure 2(a)). The high encapsulation efficiency may be due to the high ratio of polymer to DNA in the nanoparticle-DNA formulation, approximately 133:1 polymer: DNA wt. Also, this high encapsulation efficiency at pH 8 is not surprising because at this $\mathrm{pH}$ the polymer can carry enough positively charged groups to interact with the DNA efficiently $(\mathrm{pKa}=6.7$ ) [21]. This was not revealed on the measured zeta-potential $(-0.562 \mathrm{mV})$ as the PVA residue $(10-25 \%)$ is expected to shield the low positive charge at this $\mathrm{pH}$ [25]. To further demonstrate that DNA in the nanoparticle is well complexed, we mixed poly- $\beta$-aminoamide ketal, an analogous water-soluble polymer, with plasmid DNA using increasing polymer-to-DNA ratios and observed complete complexation at ratios beyond 2 Nitrogen: Phosphate ratio (corresponding to $1.4: 1$ polymer : DNA weight ratio) (Supplementary Figure 1 is available online at doi:10.1155/2012/291219).

Herein, the release of plasmid DNA from nanoparticles was monitored using Cy5-labeled DNA. The nanoparticles were very stable over a 24 -hour period at the physiological $\mathrm{pH}$ of 7.4 (Figure 2(b)), which agrees with previous results on these nanoparticles [20]. There appears to be an initial release of DNA because of the change in $\mathrm{pH}$ from that of the preparation buffer ( $\mathrm{pH} 8$ ). Complete and immediate burst release of the nanoparticles occurred when the $\mathrm{pH}$ was dropped to 5, similar to the $\mathrm{pH}$ inside an endosome, as shown by the curve jump to $100 \%$. The fast fragmentation of the polymer and release of DNA from nanoparticles occurs via a dual chemical response to low endosomal $\mathrm{pH}$, which causes particles to undergo a hydrophobic-hydrophilic switch and leads to bulk and surface degradation. Particles were also treated with phenol/chloroform to extract the plasmid DNA, which was examined by gel electrophoresis to ensure that the encapsulation procedure did not affect the integrity of the plasmid. We observed very minimal degradation of plasmid DNA (Supplementary Figure 2).

3.2. Plasmid DNA Delivery and Expression of EGFP. Next, we wanted to demonstrate that $\mathrm{pH}$-responsive nanoparticles could cross the cell membrane and deliver DNA. Our previous toxicity studies on this polymer showed good cell tolerance up to $11 \mu \mathrm{g} / \mathrm{mL}$ for 24 hours [21]; since we increased the concentration, we reduced exposure time to 4 hours. We were able to deliver up to $100 \mathrm{ng}$ of pEGFP per well in 24-well plates without observing any changes in cell morphology or any other indication of cell death under the microscope. We analyzed cell uptake kinetics of nanoparticles using Cy5-labeled pEGFP DNA. The nanoparticles were allowed to be passively endocytosed by cells over 4 hours before flow cytometry analysis. Though only 5\% of HCT116 cells showed detectable Cy5 fluorescence by 3 hours, which did not increase appreciably by 4 hours (Figure 3(a)), we believe most of the cells take up a small amount of particles that does not increase Cy5 signal appreciably. Microscopy analysis confirmed that Cy5-labeled pEGFP DNA was delivered inside cells and reached the periphery of the nucleus (Figure 3(b)). The uptake efficiency of the dual $\mathrm{pH}$ responsive nanoparticles by HCT116 cells was very similar to PLGA nanoparticles (Supplementary Figure 3). 


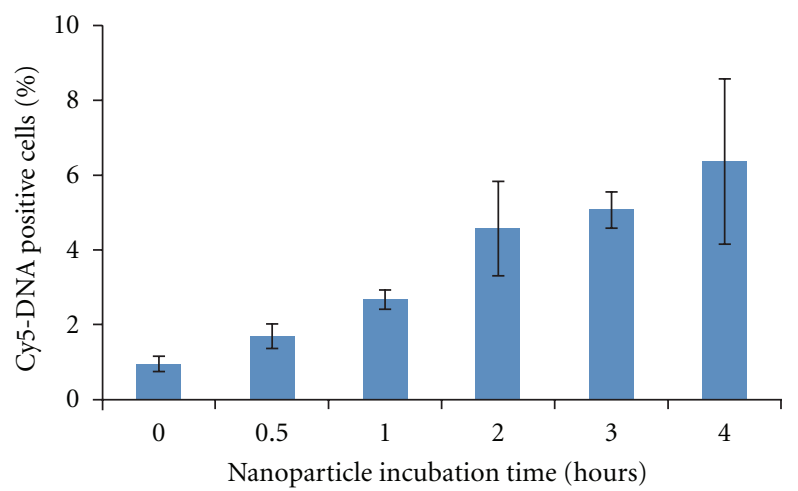

(a)

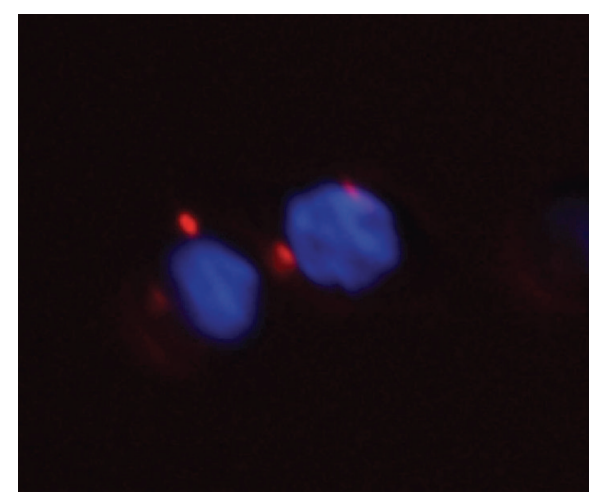

(b)

FIGURE 3: Cy5-labeled DNA delivery into cells via pH-responsive nanoparticles. HCT116 cells were incubated with pH-responsive nanoparticles containing Cy5-DNA for 0-4 hours and analyzed by flow cytometry (a) and microscopy (b) after 4 hours.
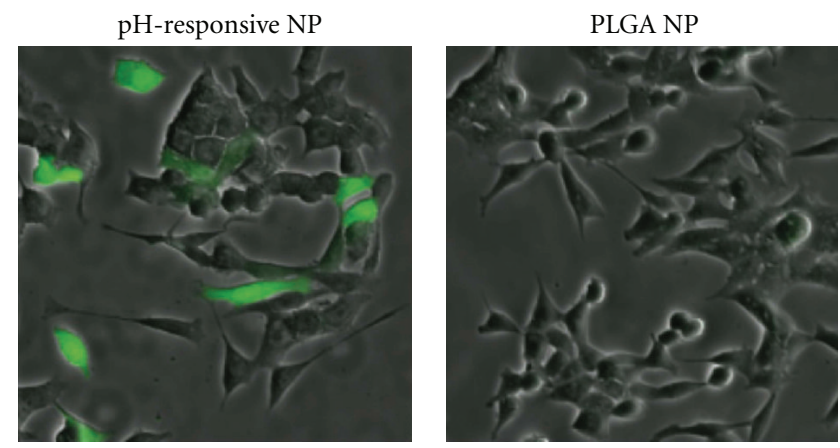

(a)

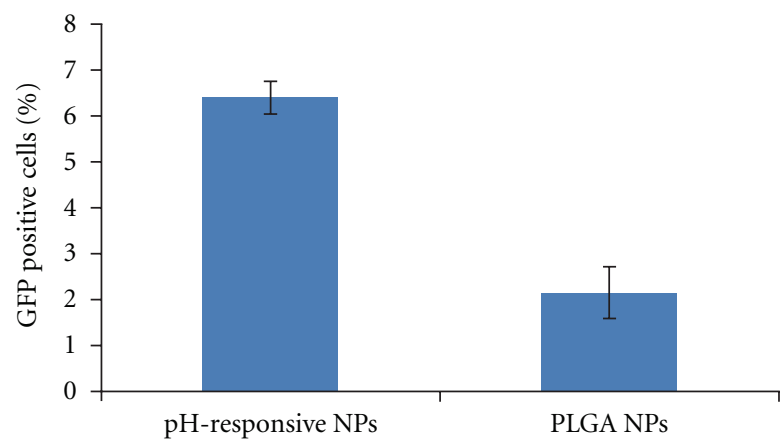

(b)

FIGURE 4: Expression of EGFP DNA with pH-responsive nanoparticles (NPs) compared to PLGA NPs: HCT116 cells were incubated with NPs for 3 hours, washed, and then incubated in media for 48 hours followed by (a) microscopy and (b) flow cytometry analysis.

Delivery of labeled plasmid into the cells via nanoparticles does not necessarily mean that EGFP will be expressed. To test expression and transfection efficiency, we incubated HCT116 cells with DNA-containing nanoparticles for 4 hours before washing to remove excess nanoparticles and incubating cells in fresh media for 48 hours. Cells treated with the dual $\mathrm{pH}$-responsive nanoparticles produced intense green fluorescence when analyzed by microscopy. In contrast, cells treated with PLGA nanoparticles containing similar amounts of pEGFP DNA produced relatively low fluorescence (Figure 4(a)). Flow cytometry analysis revealed that approximately $6 \%$ of the cell population treated with the dual $\mathrm{pH}$-responsive nanoparticles had fluorescence intensity higher than that of nontreated cells (Figure 4(b)), compared to $2 \%$ of cells treated with PLGA-DNA nanoparticles. The percentage of EGFP positive cells correlates well with the number of Cy5-positive cells, indicating that expression efficiency is high for cells that take up the nanoparticles. Additionally, comparing the intensity of EGFP-positive cells transfected with our nanoparticles or with an equal amount of DNA complexed with PEI, we show that our nanoparticles produce similar levels of EGFP expression within transfected cells (Supplementary Figure 4).

Immediate burst degradation and release of DNA from the dual $\mathrm{pH}$-responsive nanoparticles only occurs in an

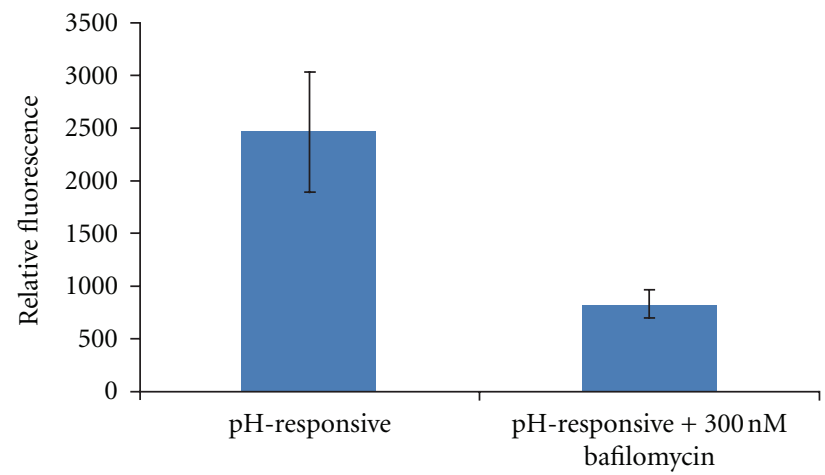

FIGURE 5: Dependence on endosomal low pH was analyzed by comparing transfection of nanoparticles in the presence or absence of $300 \mathrm{nM}$ bafilomycin A1, a V-ATPase inhibitor.

environment of low $\mathrm{pH}$, similar to that present in endosomes. This low $\mathrm{pH}$ offers the appropriate stimulus to solubilize the polymer, resulting in an accelerated degradation via ketal hydrolysis. Bafilomycin A1, an inhibitor of V-ATPase, blocks the acidification of endosomes and has been previously used to characterize the mechanism of release of $\mathrm{pH}$-dependent polyplexes and nanoparticles [26]. 
To verify that DNA release is $\mathrm{pH}$-independent, the transfection efficiency of our dual $\mathrm{pH}$-responsive nanoparticles was examined in the presence of $300 \mathrm{nM}$ bafilomycin A1. EGFP expression via nanoparticle delivery in HCT116 cells, measured by mean flow cytometry fluorescence, was reduced by $66 \%$ in the presence of bafilomycin A1 relative to nontreated cells (Figure 5). This result indicates that expression of EGFP is dependent on the acidic endosomal $\mathrm{pH}$ in order for the nanoparticle to degrade rapidly and presumably cause an endosomal burst. The mechanism of action of the dual $\mathrm{pH}$-responsive nanoparticles depends on the $\mathrm{pH}$ difference within endosomes and is thus an attractive system because particles can be maintained in stable conditions until they enter the targeted cells. Furthermore, the DNA integrity is maintained during nanoparticle degradation followed by endosomal escape. The exact mechanism for endosomal escape is still unclear, but we believe that the degraded nanoparticle causes significant instability in proton exchange and eventually bursts the endosome in a V-ATPasedependent manner.

\section{Conclusion}

Our dual $\mathrm{pH}$-responsive nanoparticles induce higher transfection efficiency than PLGA, a well-known slow-degradable polymeric material. This efficiency likely results from the nanoparticles' rapid surface and bulk degradation in response to endosomal $\mathrm{pH}$ as well as cells' tolerance for the polymer. The dual system forms a stable shield, as shown by $\mathrm{Cy} 5$ release at physiological $\mathrm{pH}$, suggesting that it may be suitable for the protection of DNA from nuclease degradation. This stability, combined with its rapid fragmentation at low $\mathrm{pH}$, means that DNA is released only if particles are endocytosed by cells. Our nanoparticles cause transfection, as demonstrated by Cy5 fluorescence following incubation of cells with particles containing labeled pDNA. The dual responsive nanoparticles produced a three-fold enhancement in EGFP expression over PLGA nanoparticles. Inhibition of V-ATPases using bafilomycin A1 demonstrates that expression of EGFP depends on low endosomal $\mathrm{pH}$.

Our fast-release system offers multiple advantages over slow-release formulations. One significant example is that these nanoparticles may also be well suited for siRNA delivery. siRNA delivery via nanoparticles has already shown promising results using well-characterized polymers like PLGA [27]. Further experiments are underway to test if siRNA can be encapsulated and delivered. Furthermore, our advanced dual response nanoparticles offer new therapeutic possibilities, especially if combined with cell-type-specific peptides or antibodies to improved cellular entry and target specificity.

\section{Acknowledgments}

The authors acknowledge the UCSD IRACDA Fellowship NIH Grant GM06852 (J. Morachis), the PhRMA Foundation, and KACST for funding this research.

\section{References}

[1] S. S. Ghosh, P. Gopinath, and A. Ramesh, "Adenoviral vectors: a promising tool for gene therapy," Applied Biochemistry and Biotechnology, vol. 133, no. 1, pp. 9-29, 2006.

[2] S. D. Li and L. Huang, "Gene therapy progress and prospects: non-viral gene therapy by systemic delivery," Gene Therapy, vol. 13, no. 18, pp. 1313-1319, 2006.

[3] E. Dormond, M. Perrier, and A. Kamen, "From the first to the third generation adenoviral vector: what parameters are governing the production yield?" Biotechnology Advances, vol. 27, no. 2, pp. 133-144, 2009.

[4] M. S. Lee, Y. L. Jang, D. P. Huynh et al., "pH-sensitive pentablock copolymer nanocapsules as nontoxic and efficient gene carriers," Macromolecular Bioscience, vol. 11, no. 6, pp. 789-796, 2011.

[5] J. A. Cohen, T. T. Beaudette, J. L. Cohen, K. E. Broaders, E. M. Bachelder, and J. M. J. Fréchet, "Acetal-modified dextran microparticles with controlled degradation kinetics and surface functionality for gene delivery in phagocytic and non-phagocytic cells," Advanced Materials, vol. 22, no. 32, pp. 3593-3597, 2010.

[6] V. Knorr, V. Russ, L. Allmendinger, M. Ogris, and E. Wagner, "Acetal linked oligoethylenimines for use as $\mathrm{pH}$-sensitive gene carriers," Bioconjugate Chemistry, vol. 19, no. 8, pp. 16251634, 2008.

[7] Z. Liu, M. Zheng, F. Meng, and Z. Zhong, "Non-viral gene transfection in vitro using endosomal $\mathrm{pH}$-sensitive reversibly hydrophobilized polyethylenimine," Biomaterials, vol. 32, no. 34, pp. 9109-9119, 2011.

[8] J. Guy, D. Drabek, and M. Antoniou, "Delivery of DNA into mammalian cells by receptor-mediated endocytosis and gene therapy," Molecular Biotechnology, vol. 3, no. 3, pp. 237-248, 1995.

[9] P. S. Tietz, K. Yamazaki, and N. F. LaRusso, "Time-dependent effects of chloroquine on $\mathrm{pH}$ of hepatocyte lysosomes," Biochemical Pharmacology, vol. 40, no. 6, pp. 1419-1421, 1990.

[10] M. Sandor, S. Mehta, J. Harris et al., "Transfection of HEK cells via DNA-loaded PLGA and P(FASA) nanospheres," Journal of Drug Targeting, vol. 10, no. 6, pp. 497-506, 2002.

[11] E. Wagner, M. Ogris, and W. Zauner, "Polylysine-based transfection systems utilizing receptor-mediated delivery," Advanced Drug Delivery Reviews, vol. 30, no. 1-3, pp. 97-113, 1998.

[12] O. Boussif, F. Lezoualc'h, M. A. Zanta et al., "A versatile vector for gene and oligonucleotide transfer into cells in culture and in vivo: polyethylenimine," Proceedings of the National Academy of Sciences of the United States of America, vol. 92, no. 16, pp. 7297-7301, 1995.

[13] U. Lungwitz, M. Breunig, T. Blunk, and A. Göpferich, "Polyethylenimine-based non-viral gene delivery systems," European Journal of Pharmaceutics and Biopharmaceutics, vol. 60, no. 2, pp. 247-266, 2005.

[14] N. Saranya, A. Moorthi, S. Saravanan, M. P. Devi, and N. Selvamurugan, "Chitosan and its derivatives for gene delivery," International Journal of Biological Macromolecules, vol. 48, no. 2, pp. 234-238, 2011.

[15] R. Jayakumar, K. P. Chennazhi, R. A. A. Muzzarelli, H. Tamura, S. V. Nair, and N. Selvamurugan, "Chitosan conjugated DNA nanoparticles in gene therapy," Carbohydrate Polymers, vol. 79, no. 1, pp. 1-8, 2010.

[16] H. L. Jiang, T. H. Kim, Y. K. Kim, I. Y. Park, M. H. Cho, and C. S. Cho, "Efficient gene delivery using chitosan-polyethylenimine hybrid systems," Biomedical Materials, vol. 3, no. 2, p. 25013, 2008. 
[17] J. M. Lü, X. Wang, C. Marin-Muller et al., "Current advances in research and clinical applications of PLGA-based nanotechnology," Expert Review of Molecular Diagnostics, vol. 9, no. 4, pp. 325-341, 2009.

[18] D. N. Nguyen, J. J. Green, J. M. Chan, R. Langer, and D. G. Anderson, "Polymeric materials for gene delivery and DNA vaccination," Advanced Materials, vol. 21, no. 8, pp. 847-867, 2009.

[19] S. A. Galindo-Rodríguez, E. Allémann, H. Fessi, and E. Doelker, "Polymeric nanoparticles for oral delivery of drugs and vaccines: a critical evaluation of in vivo studies," Critical Reviews in Therapeutic Drug Carrier Systems, vol. 22, no. 5, pp. 419-463, 2005.

[20] M. N. V. R. Kumar, S. S. Mohapatra, X. Kong, P. K. Jena, U. Bakowsky, and C. M. Lehr, "Cationic poly(lactide-coglycolide) nanoparticles as efficient in vivo gene transfection agents," Journal of Nanoscience and Nanotechnology, vol. 4, no. 8, pp. 990-994, 2004.

[21] J. Sankaranarayanan, E. A. Mahmoud, G. Kim, J. M. Morachis, and A. Almutairi, "Multiresponse strategies to modulate burst degradation and release from nanoparticles," ACS Nano, vol. 4, no. 10, pp. 5930-5936, 2010.

[22] I. K. Park, K. Singha, R. B. Arote, Y. J. Choi, W. J. Kim, and C. S. Cho, "PH-responsive polymers as gene carriers," Macromolecular Rapid Communications, vol. 31, no. 13, pp. 1122-1133, 2010.

[23] F. V. Burkersroda and A. M. Goepferich, "An approach to classify degradable polymers," Materials Research Society Symposium Proceedings, vol. 550, pp. 17-22, 1999.

[24] G. Dalwadi, H. A. E. Benson, and Y. Chen, "Comparison of diafiltration and tangential flow filtration for purification of nanoparticle suspensions," Pharmaceutical Research, vol. 22, no. 12, pp. 2152-2162, 2005.

[25] S. K. Sahoo, J. Panyam, S. Prabha, and V. Labhasetwar, "Residual polyvinyl alcohol associated with poly (D,L-lactideco-glycolide) nanoparticles affects their physical properties and cellular uptake," Journal of Controlled Release, vol. 82, no. 1, pp. 105-114, 2002.

[26] J. O. You and D. T. Auguste, "The effect of swelling and cationic character on gene transfection by $\mathrm{pH}$-sensitive nanocarriers," Biomaterials, vol. 31, no. 26, pp. 6859-6866, 2010.

[27] K. A. Woodrow, Y. Cu, C. J. Booth, J. K. Saucier-Sawyer, M. J. Wood, and W. Mark Saltzman, "Intravaginal gene silencing using biodegradable polymer nanoparticles densely loaded with small-interfering RNA," Nature Materials, vol. 8, no. 6, pp. 526-533, 2009. 

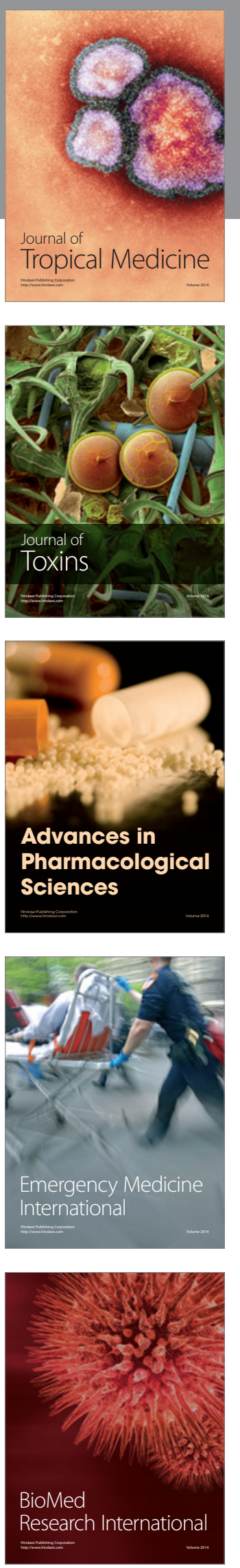
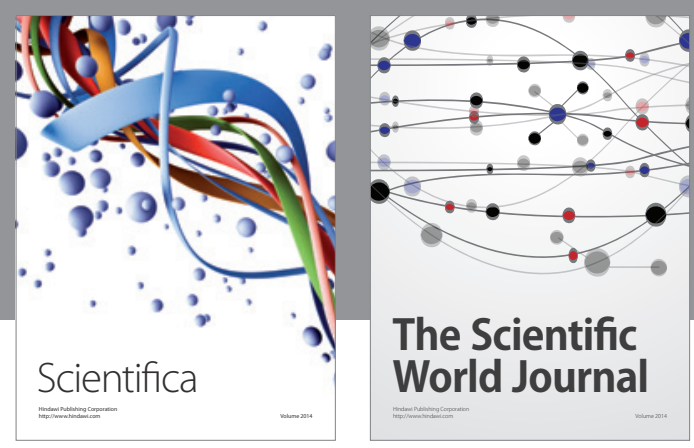

The Scientific World Journal
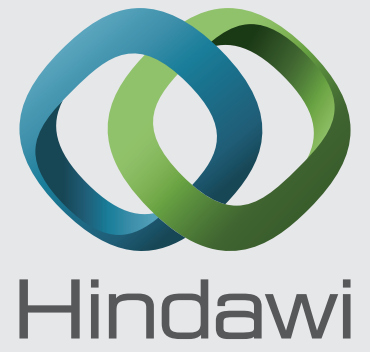

Submit your manuscripts at

http://www.hindawi.com
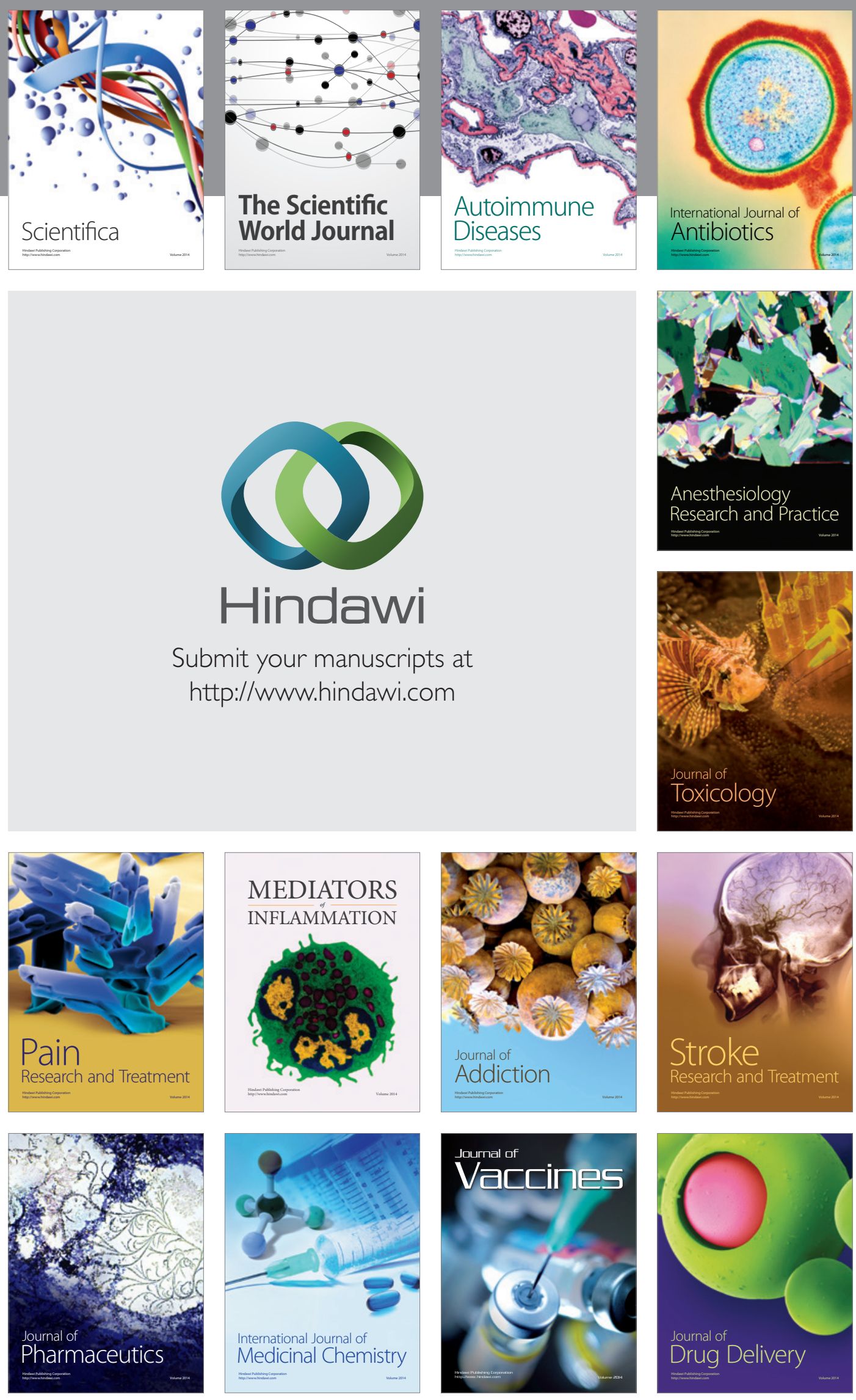